\title{
ÓlEO DE MACAÚBA COMO ALTERNATIVA PARA PRODUÇÃO DE BIODIESEL UTILIZANDO IRRADIAÇÃO COM MICRO-ONDAS
}

\author{
M. R. N. PEREIRA ${ }^{1}$, P. P. VALÉRIO ${ }^{1}$; S. C. GRANDE ${ }^{1}$, E. C. CREN ${ }^{1}$ e M. H. C. de \\ ANDRADE ${ }^{1}$ \\ ${ }^{1}$ Universidade Federal de Minas Gerais, Departamento de Engenharia Química \\ E-mail para contato: marcos.karajuca@ig.com.br
}

\begin{abstract}
RESUMO - A palmeira Macaúba (Acrocomia aculeata) produz um fruto oleaginoso com produtividade da ordem de $6000 \mathrm{~kg}$ de óleo por hectare, cuja polpa de frutos frescos apresenta teores de óleo na faixa de 50\% a $60 \%$ em base seca e na faixa de $20 \%$ a $25 \%$ em base úmida. O perfil do óleo da polpa é insaturado $(75,92 \%)$ e com predominância do ácido graxo oleico $(63,21 \%)$. O presente trabalho utiliza o óleo "bruto" extraído da polpa do fruto de macaúba para a produção de biodiesel utilizando a metodologia de transesterificação etílica homogênea via catálise básica com aquecimento por irradiação com micro-ondas. Os parâmetros de processo avaliados neste trabalho foram: razão molar etanol/óleo de 12:1, concentração de catalisador $(\mathrm{KOH})$ de 0,$5 ; 1,0$ e 1,5\% m/m de óleo e tempo de reação de 20, 40,60, 80 e 100 s. Os resultados indicaram ser possível obter eficiência de conversão de 96,61 $\pm 2,32 \%$, utilizando concentração de $1,0 \%$ de catalisador e com a reação sendo conduzida em apenas 60 segundos. Assim, o uso do óleo da polpa de macaúba e da técnica de irradiação com micro-ondas é uma alternativa promissora no cenário brasileiro para produção de biodiesel, que nesse caso incluiria também a total substituição do metanol pelo etanol, tornando o biodiesel brasileiro um combustível obtido por matérias-primas $100 \%$ renováveis.
\end{abstract}

\section{INTRODUÇÃO}

O mundo está buscando formas de suprir a demanda por energia, proporcionando o desenvolvimento de sistemas e tecnologias mais eficientes, assim como a diversificação de fontes de suprimento, especialmente de energias limpas e renováveis, destacando-se os biocombustíveis (Masiero e Lopes, 2008).

Neste cenário, atualmente destaca-se o biodiesel, um combustível renovável composto de ésteres monoalquílicos de ácidos graxos de cadeia longa, derivados de óleos vegetais ou de gorduras animais, para utilização em motores de ignição por compressão, com características físico-químicas específicas, sendo considerado como uma alternativa ao uso do diesel, constituindo uma realidade no quadro energético mundial e, em especial, no panorama brasileiro (Rezende, 2011; Dwivedi et al.,2011 apud Motasemi e Ani, 2012).

Diversas matérias-primas vegetais estão sendo objeto de estudo visando à produção desse biocombustível, sendo que este trabalho tem como foco o emprego dos frutos oleaginosos da palmeira Macaúba (Acrocomia aculeata (Jacq.) Lodd. ex Mart.), 
principalmente pela expressiva presença na forma nativa no estado de Minas Gerais e pelo elevado potencial de produtividade em óleo por hectare.

O fruto maduro é esférico, ligeiramente achatado, com diâmetro de $3 \mathrm{~cm}$ a $6 \mathrm{~cm}$, constituído pela casca ou epicarpo, cor marrom claro, com espessura de 1 a $2 \mathrm{~mm}$, sendo rígida, mas quebradiça; sob a casca encontra-se o mesocarpo ou polpa, amarelo forte, comestível, adocicada, rica em lipídeos e glicerídeos, envolvendo todo endocarpo que pode possuir uma ou duas amêndoas, sendo que das partes polpa e amêndoa se obtém dois tipos diferenciados de óleo, o óleo da polpa com perfil graxo insaturado e o óleo da amêndoa com perfil graxo saturado (Andrade et al., 2006). Os frutos são oleaginosos com teor de óleo na faixa de 50-60\% em base seca e 20-25\% em base úmida (frutos frescos), com potencial de produtividade de até $6000 \mathrm{~kg}$ de óleo por hectare (Rettore e Martins, 1983 apud Pimenta et al., 2012).

\section{MATERIAIS E MÉTODOS}

\subsection{Matéria-prima}

A reação de transesterificação homogênea via catálise básica foi realizada utilizando como matéria-prima o óleo "bruto" do mesocarpo (polpa) de macaúba, obtido no Laboratório da Macaúba do Departamento de Engenharia Química da Universidade Federal de Minas Gerais. A metodologia desenvolvida pelo Laboratório da Macaúba da UFMG consiste na extração do óleo da polpa, através das seguintes etapas: coleta, higienização, separação das partes, armazenamento em freezer, diminuição da granulometria, redução da umidade do fruto e extração a temperatura ambiente utilizando prensa mecânica.

\subsection{Análise da Composição do Óleo da Polpa de Macaúba}

O perfil dos ácidos graxos do óleo foi caracterizado através da cromatografia em fase gasosa, a técnica foi realizada em duas etapas: transformação do triglicerídeo em ácidos graxos e sua metilação (Christie, 1989; Guo et al., 2011). As análises foram realizadas em um Cromatógrafo GC-2010 Shimadzu equipado com detector por ionização de chamas.

\subsection{Caracterização Físico-química do Óleo da Polpa de Macaúba}

Os seguintes parâmetros físico-químicos foram determinados:

- Índice de acidez (método oficial Cd 3d-63 da AOCS)

- Teor de umidade (método oficial Ca 2e-84 da AOCS)

- Viscosidade cinemática a $40^{\circ} \mathrm{C}$ (ASTM D 2515)

Todos os ensaios físico-químicos foram realizados em triplicatas, sendo os resultados apresentados pelas médias e desvios padrões.

\subsection{Produção de Biodiesel}

A obtenção de biodiesel através do aquecimento por irradiação com micro-ondas foi 
realizado em forno doméstico (sem adaptação) de micro-ondas Electrolux, modelo NEF 28, $18 \mathrm{~L}, 1020 \mathrm{~W}$, com frequência de $2450 \mathrm{MHz}$. Os parâmetros analisados foram razão molar etanol/óleo (etanol com 99,8\% de pureza) de 12:1; concentração de catalisador (KOH com $85 \%$ de pureza) de $0,5,1,0$ e $1,5 \% \mathrm{~m} / \mathrm{m}$ em relação ao óleo, potência nominal máxima do aparelho de micro-ondas $(1020 \mathrm{~W})$ e tempos reacionais de 20, 40, 60, 80 e 100 s. Ressalte-se que a utilização de excesso de etanol ocorreu principalmente em função de dois fatores: necessidade de deslocar a reação no sentido da formação dos produtos e; a perda de etanol durante a reação por volatilização, pois o equipamento de micro-ondas disponível para a pesquisa não possuía um sistema de refluxo. Todas as reações ocorreram em erlenmeyers de $125 \mathrm{~mL}$ contendo a massa de $20 \mathrm{~g}$ de óleo, que foi homogeneizada por 3 minutos a aproximadamente $200 \mathrm{rpm}$ em agitador magnético MS 300 Magnetic Stirrer, antes de ser submetida à irradiação com micro-ondas.

Todos os ensaios foram realizados em duplicatas, sendo os resultados apresentados pelas médias e desvios padrões.

\subsection{Purificação do Biodiesel}

Após a reação de transesterificação, as amostras foram levadas a centrifuga Excelsa II $206 \mathrm{BL}$, por 10 minutos, a uma velocidade de $3200 \mathrm{rpm}$, para a separação das fases, sendo a fase menos densa, rica em ésteres etílicos e a mais densa, rica em glicerol.

Em um primeiro momento buscou-se purificar o biodiesel por meio da realização de três lavagens consecutivas (conforme literatura): a primeira utilizando solução de $\mathrm{HCl} 0,1 \mathrm{~mol} / \mathrm{L}$ e a segunda e terceira utilizando água destilada até a obtenção de pH 7,0. Entretanto, durante esse processo de purificação ocorreu formação de emulsão estável.

Assim, com o objetivo de promover a quebra da emulsão, vários procedimentos foram previamente testados. Os testes culminaram na metodologia com resultado positivo, que prevê o uso de uma mistura polar/apolar de 1:1 em volume de álcool etílico $(95 \%) /(2,2,4$ trimetilpentano), em cada etapa de lavagem.

Entretanto, a adição de solvente no biodiesel acarreta em uma nova etapa no processo de purificação, que consiste em retirar o excesso do solvente, que neste trabalho, foi realizado através de sua volatização em uma estufa microprocessada com circulação forçada de ar (42L) a uma temperatura de $105^{\circ} \mathrm{C}$ por 150 minutos. A temperatura de $105^{\circ} \mathrm{C}$ foi utilizada neste processo de forma a propiciar a remoção da água e dos solventes adicionados.

O tempo para completa volatização dos solventes de 150 minutos foi determinado através da técnica de gravimetria, utilizando a seguinte metodologia: as amostras de biodiesel foram retiradas da estufa microprocessada com circulação forçada de ar a cada 15 minutos e o valor da massa determinado em uma balança da marca Adventurer Ohaus. Por este procedimento foi observado que após 150 minutos as amostras na estufa microprocessada resultavam em um valor de massa estabilizado, indicando que todo o solvente havia sido volatilizado. A partir dessas etapas o biodiesel foi reservado para a análise do teor de ésteres etílicos. 


\subsection{Teor de Ésteres Etílicos}

O teor de ésteres etílicos foi determinado empregando o método analítico de viscosimetria, consistindo em uma técnica no qual se correlaciona matematicamente a variação do teor de ésteres alquílicos com a variação da viscosidade (Knothe et al., 2005; Sousa et al., 2013). A equação (1) pode ser utilizada para o monitoramento da transesterificação de diferentes óleos vegetais, desde que apresentem viscosidades próximas à viscosidade do óleo de soja ou apresentem um alto teor de ésteres etílicos (Sousa et al., 2013). A viscosidade foi determinada utilizando o viscosímetro automático AVS 250 Schott.

$$
\text { Teor de ésteres etílicos }(\%)=160 . \mathrm{e}^{(-\mathrm{v} / 9,0)}
$$

Onde, $v$ é a viscosidade cinemática a $40^{\circ} \mathrm{C}$

\section{RESULTADOS E DISCUSSÕES}

\subsection{Caracterização dos Ácidos Graxos}

A composição do óleo da polpa de macaúba está demonstrada na Tabela 01.

Tabela 01- Percentual dos ácidos graxos na amostra de óleo da polpa de macaúba

\begin{tabular}{|c|c|c|c|}
\hline $\begin{array}{c}\text { Tipo de cadeia } \\
\text { Alquílica } \\
\end{array}$ & Nomenclatura IUPAC & $\begin{array}{c}\text { Nomenclatura } \\
\text { Usual }\end{array}$ & $\begin{array}{c}\text { Área percentual } \\
(\%)\end{array}$ \\
\hline $\mathrm{C} 4: 0$ & Ácido butanoico & Butírico & 1,65 \\
\hline C16:0 & Ácido hexadecanóico & Palmítico & 18,25 \\
\hline C16:1 & Ácido 9-hexadecenóico & Palmitoleico & 1,72 \\
\hline C18:0 & Ácido octadecanóico & Esteárico & 3,45 \\
\hline $\mathrm{C} 18: \ln 9 \mathrm{c}$ & Ácido 9-octadecenóico & Oleico & 63,21 \\
\hline $\mathrm{C} 18: 2 \mathrm{n} 6 \mathrm{c}$ & Ácido 9,12-octadecadienóico & Linoleico & 9,21 \\
\hline $\mathrm{C} 18: 3 \mathrm{n} 3$ & Ácido 9,12,15-octadecatrienóico & Linolênico & 0,84 \\
\hline C20:1n9 & Ácido 9-eicosenóico & Gadoleico & 0,85 \\
\hline $\mathrm{C} 22: 0$ & Ácido docosanóico & Behênico & 0,12 \\
\hline \multirow[t]{2}{*}{$\mathrm{C} 24: \ln 9$} & \multirow[t]{2}{*}{ Ácido 15-tetracosenóico } & \multirow[t]{2}{*}{ Nervônico } & 0,09 \\
\hline & & & $\begin{array}{l}\text { Insaturado: } 75,92 \\
\text { Saturado: } 23,47 \\
\text { Total*: } 99,39\end{array}$ \\
\hline
\end{tabular}

$\mathrm{n}=$ carbono onde está localizado a primeira insaturação, $\mathrm{c}=$ cis

IUPAC = International Union of Pure and Applied chemistry

*A área total é a soma de todas as áreas compreendidas no intervalo no qual se pode detectar os picos do padrão supelco 37 , assim, a área total pode não corresponder à soma das áreas dos ésteres que apresentam tempos de retenção similares ao do supelco 37. 
Analisando a Tabela 01 constata-se que o óleo da polpa de macaúba é composto principalmente pelo ácido oleico $(63,21 \%)$, ácido palmítico $(18,25 \%)$, ácido linoleico $(9,21 \%)$ e ácido esteárico $(3,45 \%)$.

\subsection{Análises Físico-químicas do Óleo da Polpa de Macaúba}

Os parâmetros físico-químicos da matéria-prima, principalmente o índice de acidez, teor de umidade e viscosidade cinemática são fundamentais para determinar a viabilidade da produção do biodiesel e a definição da melhor rota a ser utilizada. Na Tabela 02 são apresentados os resultados das análises físico-químicas do óleo da polpa de macaúba.

Tabela 02 - Propriedades físico-químicas do óleo da polpa de macaúba

\begin{tabular}{|c|c|}
\hline Parâmetro & Valor \\
\hline Índice de acidez $(\mathrm{mg} \mathrm{KOH} / \mathrm{g})$ & $4,03 \pm 0,18$ \\
Índice de acidez em ácido oléico $(\%)$ & $2,02 \pm 0,08$ \\
Teor de umidade $(\%)$ & $0,27 \pm 0,05$ \\
Viscosidade cinemática a $40^{\circ} \mathrm{C}\left(\mathrm{mm}^{2} / \mathrm{s}\right)$ & $40,04 \pm 0,95$ \\
\hline
\end{tabular}

Assim, os resultados das análises físico-químicas do óleo diretamente extraído da polpa do fruto de macaúba, obtido conforme procedimentos de colheita, pós-colheita, preparo e extração, estabelecidos no Laboratório da Macaúba, é adequado para uso em processos de produção de biodiesel por transesterificação por catálise homogênea.

\subsection{Catálise Etílica Homogênea}

\subsubsection{Transesterificação Utilizando $0,5 \% \mathrm{~m} / \mathrm{m}$ de KOH}

Os resultados da análise da viscosidade cinemática a $40^{\circ} \mathrm{C}$ e do teor de ésteres etílicos, para o processo utilizando razão molar $12: 1$ etanol/óleo e $0,5 \% \mathrm{~m} / \mathrm{m}$ de catalisador $(\mathrm{KOH})$, estão apresentados na Tabela 03.

Tabela 03 - Viscosidade cinemática e teor de ésteres etílicos para 0,5\% de $\mathrm{KOH}$

\begin{tabular}{|c|c|c|c|}
\hline Amostra & Tempo (s) & Viscosidade cinemática $\left(\mathrm{mm}^{2} / \mathrm{s}\right)$ & Teor de ésteres etílicos $(\%)$ \\
\hline M 01 & 20 & $24,82 \pm 0,76$ & $10,15 \pm 0,86$ \\
M 02 & 40 & $15,10 \pm 0,49$ & $29,88 \pm 1,65$ \\
M 03 & 60 & $8,11 \pm 0,39$ & $64,97 \pm 2,97$ \\
M 04 & 80 & $6,67 \pm 0,18$ & $76,25 \pm 1,54$ \\
M 05 & 100 & $13,75 \pm 0,80$ & $34,72 \pm 3,07$ \\
\hline
\end{tabular}

De acordo com esses resultados, constata-se a influência do tempo de reação no processo de conversão em ésteres etílicos. Observa-se que a reação de transesterificação atinge um teor máximo de ésteres etílicos $(76,25 \pm 1,54 \%)$ e que após esse tempo ocorre uma diminuição na taxa de conversão. Esse fato pode ser explicado pela provável ocorrência de 
reações paralelas de saponificação e neutralização, que se constituem em reações indesejáveis que reduzem o teor de ésteres etílicos.

Adicionalmente, pode-se afirmar que a irradiação com micro-ondas, utilizando 0,5\% de catalisador, possui grande sensibilidade em relação ao parâmetro tempo de reação, pois a variação de $20 \mathrm{~s}$, como observado nas amostras M 04 e M 05, provoca uma redução de $41,53 \%$ no teor de conversão, fato este que também pode ser explicado pela ocorrência de reações paralelas. Outro provável fator é a redução da concentração do agente transesterificante, o etanol, que está sendo volatilizado, pois o aparelho de micro-ondas não possui um sistema de adaptação de refluxo.

\subsubsection{Transesterificação Utilizando $1,0 \% \mathrm{~m} / \mathrm{m}$ de KOH}

Os resultados da análise da viscosidade cinemática a $40^{\circ} \mathrm{C}$ e do teor de ésteres etílicos, para o processo utilizando razão molar 12:1 etanol/óleo e $1,0 \% \mathrm{~m} / \mathrm{m}$ de catalisador $(\mathrm{KOH})$, estão apresentados na Tabela 04.

Tabela 04 - Viscosidade cinemática e teor de ésteres etílicos para 1,0\% de KOH

\begin{tabular}{|c|c|c|c|}
\hline Amostra & Tempo $(\mathrm{s})$ & Viscosidade cinemática $\left(\mathrm{mm}^{2} / \mathrm{s}\right)$ & Teor de ésteres etílicos $(\%)$ \\
\hline M 06 & 20 & $12,70 \pm 0,01$ & $39,01 \pm 0,31$ \\
M 07 & 40 & $5,56 \pm 0,40$ & $86,26 \pm 3,83$ \\
M 08 & 60 & $4,54 \pm 0,21$ & $96,61 \pm 2,32$ \\
M 09 & 80 & $4,78 \pm 0,23$ & $94,07 \pm 2,40$ \\
M 10 & 100 & $8,31 \pm 0,69$ & $63,55 \pm 4,85$ \\
\hline
\end{tabular}

Conforme resultados da Tabela 04, confirma-se a existência de um tempo adequado para a obtenção de um teor máximo de ésteres etílicos, que neste caso foi obtido após $60 \mathrm{~s}$ de reação. Após ter atingido a conversão máxima em ésteres etílicos $(96,61 \pm 2,32 \%)$, a provável ocorrência de reações paralelas, principalmente saponificação e neutralização, provocaram um aumento da viscosidade e consequentemente uma redução no teor de ésteres etílicos.

Adicionalmente, verifica-se que para a concentração de $1,0 \%$ de $\mathrm{KOH}$ a $60 \mathrm{~s}$, obteve-se um rendimento de $31,64 \%$ maior que o obtido usando $0,5 \%$ de $\mathrm{KOH}$ a $60 \mathrm{~s}$, constatando assim, a influência da concentração do catalisador na conversão de ésteres etílicos. Ainda, convém destacar que para a melhor condição encontrada ao se utilizar 1,0\% de catalisador, o valor de teor de ésteres etílicos obtido foi $20,36 \%$ maior que o obtido na melhor condição para a concentração de $0,5 \%$ de catalisador.

\subsubsection{Transesterificação Utilizando $1,5 \%$ m/m de KOH}

Os resultados da análise da viscosidade cinemática a $40^{\circ} \mathrm{C}$ e do teor de ésteres etílicos, para o processo utilizando razão molar 12:1 etanol/óleo e 1,0\% m/m de catalisador $(\mathrm{KOH})$, estão apresentados na Tabela 05. 
Tabela 05 - Viscosidade cinemática e teor de ésteres etílicos para 1,5\% m/m de KOH

\begin{tabular}{|c|c|c|c|}
\hline Amostra & Tempo $(\mathrm{s})$ & Viscosidade cinemática $\left(\mathrm{mm}^{2} / \mathrm{s}\right)$ & Teor de ésteres etílicos $(\%)$ \\
\hline M 11 & 20 & $5,51 \pm 0,17$ & $86,74 \pm 1,68$ \\
M 12 & 40 & $5,81 \pm 0,13$ & $83,89 \pm 1,17$ \\
M 13 & 60 & $6,96 \pm 0,06$ & $73,83 \pm 0,45$ \\
M 14 & 80 & $9,00 \pm 0,78$ & $58,86 \pm 5,13$ \\
M 15 & 100 & $15,90 \pm 0,08$ & $27,34 \pm 0,26$ \\
\hline
\end{tabular}

Analogamente ao que foi encontrado nos resultados anteriormente descritos, fica certificado a existência de um tempo ótimo de reação no qual se alcança uma maior conversão dos triglicerídeos em ésteres etílicos. Contudo, com o uso da concentração de catalisador de $1,5 \%$, esse tempo é provavelmente menor do que 20 segundos. Observou-se que a reação não atingiu a conversão total e que o teor de ésteres etílicos de $86,74 \pm 1,68 \%$ foi obtido após $20 \mathrm{~s}$, sendo o valor máximo de conversão de todos os ensaios realizados utilizando $1,5 \%$ de catalisador.

\section{CONCLUSÕES}

Sabendo que o Programa Nacional de Produção e Uso de Biodiesel (PNPB) tem como principal objetivo garantir a produção economicamente viável do biocombustível, proporcionando a inclusão social e o desenvolvimento regional, através da diversificação do uso de matérias-primas, este trabalho demonstrou o potencial de produção do biodiesel, empregando como matéria-prima o óleo da polpa da palmeira Macaúba (Acrocomia aculeata). Os ensaios de produção de biodiesel por aquecimento com irradiação em forno de micro-ondas, mesmo empregando um aparelho de micro-ondas convencional doméstico, sem qualquer adaptação, indicam que o uso deste tipo de equipamento é tecnicamente promissor, havendo a necessidade de se adequar os parâmetros de processo concentração de catalisador e tempo de reação em função da potência de cada equipamento. A partir desta adequação, a eficiência do processo para a obtenção de um rendimento elevado pode ser alcançada com tempo de reação relativamente curto, tornando o uso da técnica de irradiação com microondas economicamente viável, principalmente considerando processamento contínuo e grandes escalas de produção. Destaca-se que o uso dessa técnica de aquecimento pode ser uma opção de adaptação nas atuais usinas de produção de biodiesel brasileira, que nesse caso incluiria também a total substituição do metanol pelo etanol, atrativa sob o ponto de vista estratégico e ambiental, pois o Brasil é considerado o maior produtor mundial de etanol a partir de cana-de-açúcar, assim o biodiesel brasileiro será um combustível obtido por matérias-primas $100 \%$ renováveis.

\section{AGRADECIMENTOS}

Os autores agradecem a FINEP, EMBRAPA Agroenergia, CAPES, CNPq e o Departamento de Engenharia Química da Escola de Engenharia da UFMG pelo apoio financeiro e Bolsas de mestrado concedidas. 


\section{REFERÊNCIAS BIBLIOGRÁFICAS}

ANDRADE, M. H. C.; VIEIRA, A. S.; AGUIAR, H. F.; CHAVES, J. F. N.; NEVES, R. M.

P. S.; MIRANDA, T. L. S.; SALUM, A. Óleo do Fruto da Palmeira Macaúba Parte I: Uma Aplicação Potencial Para Indústrias de Alimentos, Fármacos e Cosméticos. In: II ENBTEQ - Encontro Brasileiro sobre Tecnologia na Indústria Química / III Seminário ABIQUIM de Tecnologia, 2006, São Paulo. Anais do II ENBTEQ - Encontro Brasileiro sobre Tecnologia na Indústria Química. São Paulo: ABEQ, 2006. v. 1.

CHRISTIE, W. W. Gas Chromatography and Lipids. Oxford, Pergamon Press, 1989.

GUO, H.; HU, C.; QIAN, J. Determination of Underivatized Long Chain Fatty Acids Using HPLC with an Evaporative Light-Scattering Detector. J. Am. Oil Chem. Soc., v. 89, p. 183-187, 2011.

KNOTHE, G.; GERPEN, J. V.; KRAHL, J. The Biodiesel Handbook. Illinois, AOCS Press, 2005.

MASIERO, L.; LOPES, H. Etanol e biodiesel como recursos energéticos alternativos: perspectivas da América Latina e da Ásia. Rev. Bras. Polít. Int., v. 51, n. 2, p. 60-79, 2008 .

MOTASEMI, F.; ANI, F. N. A review on microwave-assisted production of biodiesel. Renew. Sust. Energ. Rev., v. 16, p. 4719-4733, 2012.

PIMENTA, T. V.; ANDRADE, M. H. C.; ANTONIASSI, R. Extração, Neutralização e Caracterização dos Óleos do Fruto da Macaúba (Acrocomia Aculeata). XIX Congresso Brasileiro de Engenharia Química, Búzios, Rio de Janeiro, p. 4031-4040, 2012.

REZENDE, D. B. Esterificação e Transesterificação de Óleos de Macaúba com Elevada e Baixa Acidez Catalisadas por Resinas de Troca Iônica. Dissertação (Mestrado em Engenharia Química), Universidade Federal de Minas Gerais, Belo Horizonte, 2011.

SOUSA, F. P.; LUCIANO, M. A.; PASA, V. M. D. Thermogravimetry and Viscometry for Assessing the Ester Content (FAME and FAEE). Fuel Process. Technol., v. 109, p. 133$140,2013$. 